\title{
TINJAUAN PERHITUNGAN BANGUNAN BAWAH (SUB STRUCTURE) PROYEK JEMBATAN SUNGAI JINAL (RUAS DESA DANAU CARAMIN (BATAS KABUPATEN HULU SUNGAI UTARA)-BATAS KOTA AMUNTAI)
}

\author{
Muhammad Indra Amanda ${ }^{1}$, Ruliana Febrianty ${ }^{2}$, Tezar Aulia Rachman ${ }^{3}$ \\ ${ }^{1}$ Universitas Islam Kalimantan Muhammad Arsyad Al Banjari Banjarmasin (Mahasiswa) \\ ${ }^{2}$ Universitas Islam Kalimantan Muhammad Arsyad Al Banjari Banjarmasin (Dosen) \\ ${ }^{3}$ Universitas Islam Kalimantan Muhammad Arsyad Al Banjari Banjarmasin (Dosen) \\ Email: indraamandaamd@gmail.com/HP 087815976748
}

\begin{abstract}
ABSTRAK
Jembatan Sungai Jinal berada di ruas Desa Danau Caramin (Batas Kabupaten Hulu Sungai Utara)-Batas Kota Amuntai. Perencanaan struktur jembatan Sungai Jinal direncanakan pada tahun 2015 menggunakan peraturan pembebanan untuk jembatan RSNI 2005, seiring dengan waktu, standart tersebut perlu diperbarui sesuai dengan kondisi terkini menggunakan SNI 1725:2016.

Perhitungan pembebanan yang dilakukan pada abutment jembatan sungai Jinal menggunakan SNI 1725:2016 dan untuk standar perencanaan ketahanan gempa untuk jembatan menggunakan SNI 2883:2013. Analisa perhitungan daya dukung tiang aksial menggunakan metode pendekatan statis yang terdiri dari data N-SPT, sedangkan untuk perhitungan daya dukung tiang lateral menggunakan metode pendekatan Suyono. Analisa perhitungan penulangan pada abutment menggunakan RSNI T-12-2004.

Berdasarkan hasil analisa perhitungan diperoleh hasil daya dukung tiang sudah mampu menahan gaya-gaya yang bekerja pada jembatan dengan nilai daya dukung tiang tunggal sebesar 128,6 ton. Sedangkan pada perhitungan penulangan terdapat perbedaan hasil dimensi tulangan, dimana pada pilecap dimensi perencana tulangan tarik D19-150 sedangkan perhitungan D22-150, tulangan susut D19-100 sedangkan perhitungan D13100, tulangan geser D10-300/300 sedangkan perhitungan D13-200/200. Pada penulagan breaswall dimensi tulangan tarik D25-120 sedangkan perhitungan D25-100, tulangan tekan D25-120 sedangkan perhitungan D19100, tulangan susut D16-150 sedangkan perhitungan D19-125. Perbedaan hasil perhitungan disebabkan oleh peraturan pembebanan yang digunakan, standar perencanaan ketahanan gempa dan bentuk abutment.
\end{abstract}

Kata Kunci: Jembatan; SNI; Pembebanan

\section{ABSTRACT}

The Jinal River Bridge is in the segment of Danau Caramin Village (District Line Hulu Sungai Utara)-Amuntai City Limits. Planning of the structure of the Sei bridge. The planning of the Jinal river bridge structure is planned in 2015 using the loading regulations for the 2005 RSNI bridge, over time, the standard needs to be updated according to the current conditions using SNI 1725: 2016.

The loading calculations performed on the abutment of the Jinal river bridge use SNI 1725: 2016 and for earthquake endurance planning standards for bridges using SNI 2883: 2013. Analysis of calculation of axial pole carrying capacity using static approach method consisting of documents (N-SPT), while for calculating the carrying capacity of lateral poles using the Suyono approach method. Analysis of calculation of reinforcement on abutments using T-12-2004 RSNI.

Based on the results of the calculation analysis obtained the results of the carrying capacity of the pole is able to withstand the forces acting on the bridge with a single bearing carrying capacity of 128.6 tons. Whereas in the calculation of reinforcement there are differences in reinforcement dimensions results, where in the pilecap dimension the reinforcement planner pulls D19-150 while the calculation of D22-150, D19-100 shrinkage reinforcement while D13-100 calculation, shear reinforcement D10-300 / 300 while calculating D13-200 / 200. In the transmission of breaswall the dimensions of reinforcement are D25-120 while the calculation of D25-100, pressurization press D25-120 while calculation of D19-100, shrinkage reinforcement D16-150 while calculation D19-125. The difference in the results of calculations is caused by the loading regulations used, the standard planning of earthquake resistance and the form of abutments.

Keywords: Bridge; SNI; Loading. 


\section{PENDAHULUAN}

Jembatan Sungai Jinal terletak di Amuntai yang menghubungkan ruas Desa Danau Caramin (Batas Kabupaten Hulu Sungai Utara)-Batas Kota Amuntai, jembatan direncanakan jembatan kelas A dengan panjang rancana 30,6 meter, dengan masa perencanaan yaitu pada tahun 2015. Perencanaan Jembatan Sungai Jinal terdiri dari pekerjaan struktur jembatan dan oprit dengan pekerjaan stuktur jembatan yang terdiri dari bangunan atas (superstructure) dan bangunan bawah (substructure).

Dalam hal ini penulis ingin meninjau ulang perencanaan Jembatan Sungai Jinal dengan menggunakan peraturan terbaru SNI 1725:2016 tentang Pembebanan Untuk Jembatan, dikarenakan perencanaan Jembatan Sungai Jinal direncanakan pada tahun 2015 dipastikan perencanaan tersebut masih menggunakan peraturan yang terdahulu yaitu RSNI 2005. Adapun beberapa ketentuan teknis yang disesuaikan dari peraturan RSNI 2005 dengan SNI 1725:2016 antara lain distribusi beban lajur dalam arah melintang, faktor distribusi beban truk, kombinasi beban, beban gempa, beban angin, dan beban fatik. Sehingga ketentuan teknis yang disesuaikan tersebut apakah dapat memberikan pengaruh dalam hasil perhitungan yang didapat.

Berdasarkan kondisi tersebut penulis ingin meninjau ulang beban-beban yang bekerja pada struktur bangunan bawah jembatan Sungai Jinal dengan menggunakan standar terbaru SNI 1725:2016. Karena RSNI 2005 seiring dengan waktu, standart tersebut perlu diperbarui sesuai dengan kondisi terkini.

Permasalahan dari penelitian ini adalah bagaimana perbedaan konstruksi bangunan bawah (sub structure) Jembatan Sungai Jinal yang menggunakan RSNI 2005 dengan SNI 1725:2016 yang merupakan standar peraturan terbaru di Indonesia untuk pembebanan jembatan, antara lain meliputi, bagaimana daya dukung tiang pancang pada abutment dan bagaimana penulangan pada abutment Jembatan Sungai Jinal.

Tujuan dari penelitian ini adalah untuk mengetahui apakah terjadi perbedaan yang signifikan di konstruksi perencanaan Jembatan Sungai Jinal yang menggunakan RSNI 2005 dengan SNI 1725:2016 yang merupakan standar peraturan terbaru untuk pembebanan jembatan, sedangkan batasan masalah pada penelitian ini adalah perancangan ulang hanya pada struktur bangunan bawah (substructure) Jembatan Sungai Jinal yang meliputi, abutment dan tiang pondasi. Pembebanan yang digunakan terdiri dari beban permanen (berat sendiri (MS), beban mati tambahan (MA), tekanan tanah di belakang abutment (TA)), beban lalu lintas, gaya rem, temperature, beban angin dan beban gempa.

\section{METODE PENELITIAN}

pengolahan data yang didapat pada penelitian ini digunakan untuk menghitung beberapa beban yang terjadi pada abutment jembatan dengan menggunakan SNI 1725:2016, selain itu juga untuk mengetahui berapa besaran daya dukung tiang dan berapa dimensi penulangan yang didapatkan. Untuk bagian alir penulisan tugas akhir dapat dilihat pada gambar 1 .

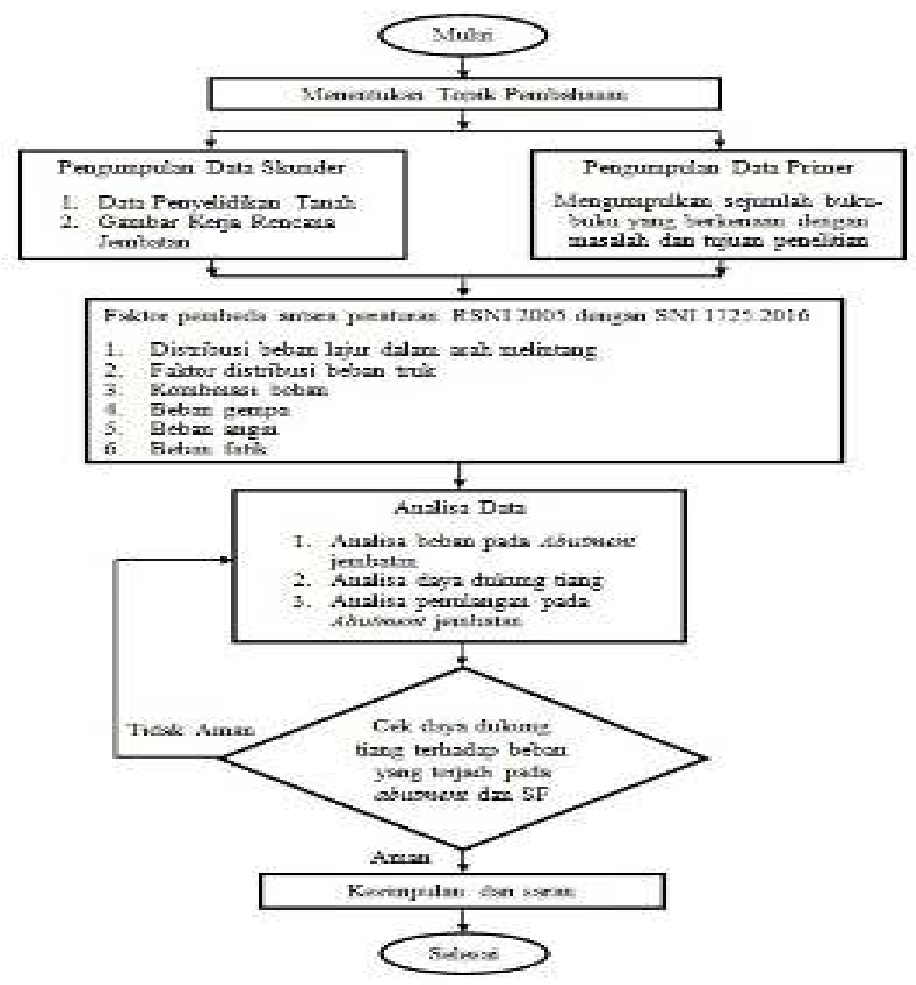

Gambar 1 Bagan alir penulisan tugas akhir 


\section{HASIL DAN PEMBAHASAN}

Daya Dukung Tiang Pancang

Berdasarkan analisa perhitungan beban dan daya dukung tiang pada abutment diperoleh hasil rekap pembebanan yang dapat dilihat pada tabel 1 dibawah ini:

Tabel 1 Rekap kombinasi beban kerja pada abutment

\begin{tabular}{|c|c|c|c|c|c|}
\hline \multirow{2}{*}{ KOMBINASI } & $\mathrm{Vy}$ & $\mathrm{Hx}$ & $\mathrm{Hy}$ & $\mathbf{M x}$ & My \\
\cline { 2 - 6 } & $(\mathbf{k N})$ & $\mathrm{kN} \cdot \mathbf{m}$ & $\mathrm{kN} \cdot \mathbf{m}$ & $\mathbf{k N} \cdot \mathbf{m}$ & $\mathrm{kN} \cdot \mathbf{m}$ \\
\hline Daya layan-1 & $6.327,79$ & $1.176,329$ & 28,520 & 0,000 & $2.159,268$ \\
\hline Daya layan-2 & $7.027,75$ & $1.201,192$ & 0,000 & 0,000 & $2.275,397$ \\
\hline Daya layan-3 & $5.861,15$ & $1.126,329$ & 0,000 & 0,000 & $1.734,473$ \\
\hline Daya layan-4 & $3.994,59$ & 876,192 & 20,279 & 0,000 & 373,176 \\
\hline Kuat-5 & $3.994,59$ & 876,192 & 48,799 & 0,000 & 496,970 \\
\hline Ekstrem-6 & $6.327,79$ & $3.017,100$ & $1.091,181$ & $2.061,736$ & $5.925,178$ \\
\hline
\end{tabular}

(Sumber: Data diolah :2018)

Sedangkan untuk daya dukung tiang pancang yang digunakan dalam perhitungan berdasarkan pada data N-SPT diperoleh nilai daya dukung ijin tiang $\left(\mathrm{Q}_{\text {ult }}\right)$ sebesar 472,1 ton dengan $\mathrm{SF}=2,5$ maka diperoleh $\left(\mathrm{Q}_{\mathrm{ijin}}\right)$ sebesar 188,8 ton. Karena tiang pancang yang direncanakan merupakan tiang pancang kelompok, sehingga efisiensi

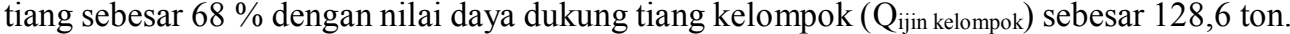

Untuk perhitungan distribusi gaya aksial akibat beban normal $(\mathrm{P})$, momen arah $\mathrm{x}\left(\mathrm{M}_{\mathrm{x}}\right)$ dan momen arah y $\left(\mathrm{M}_{\mathrm{y}}\right)$ pada pile cap dapat dilihat pada tabel 2 berikut:

Tabel 2 Distribusi beban struktur atas ke kelompok tiang

\begin{tabular}{|c|c|c|c|c|c|c|c|c|}
\hline \multirow{2}{*}{ No. Tiang } & \multicolumn{2}{|c|}{ Koordinat } & \multirow{2}{*}{$x^{2}$} & \multirow{2}{*}{$Y^{2}$} & \multirow{2}{*}{$\mathrm{V} / \mathrm{n}$} & \multirow{2}{*}{$M_{y}{ }^{*} X_{i} / \sum x^{2}$} & \multirow{2}{*}{$M_{x}{ }^{*} Y_{i} / \sum y^{2}$} & \multirow{2}{*}{$\mathrm{P}$ (ton) } \\
\hline & $\mathrm{X}$ & $\mathrm{Y}$ & & & & & & \\
\hline 1 & $-4,65$ & 0,90 & 21,6 & 0,81 & 69,6 & $-20,479$ & 16,363 & 65,5 \\
\hline 2 & $-3,10$ & 0,90 & 9,61 & 0,81 & 69,6 & $-13,652$ & 16,363 & 72,3 \\
\hline 3 & $-1,55$ & 0,90 & 2,4 & 0,81 & 69,6 & $-6,826$ & 16,363 & 79,2 \\
\hline 4 & 0,00 & 0,90 & 0 & 0,81 & 69,6 & 0,000 & 16,363 & 86,0 \\
\hline 5 & 1,55 & 0,90 & 2,4 & 0,81 & 69,6 & 6,826 & 16,363 & 92,8 \\
\hline 6 & 3,10 & 0,90 & 9,61 & 0,81 & 69,6 & 13,652 & 16,363 & 99,6 \\
\hline 7 & 4,65 & 0,90 & 21,6 & 0,81 & 69,6 & 20,479 & 16,363 & 106,5 \\
\hline 8 & $-4,65$ & $-0,90$ & 21,6 & 0,81 & 69,6 & $-20,479$ & $-16,363$ & 32,8 \\
\hline 9 & $-3,10$ & $-0,90$ & 9,61 & 0,81 & 69,6 & $-13,652$ & $-16,363$ & 39,6 \\
\hline 10 & $-1,55$ & $-0,90$ & 2,4 & 0,81 & 69,6 & $-6,826$ & $-16,363$ & 46,4 \\
\hline 11 & 0,00 & $-0,90$ & 0 & 0,81 & 69,6 & 0,000 & $-16,363$ & 53,3 \\
\hline 12 & 1,55 & $-0,90$ & 2,4 & 0,81 & 69,6 & 6,826 & $-16,363$ & 60,1 \\
\hline 13 & 3,10 & $-0,90$ & 9,61 & 0,81 & 69,6 & 13,652 & $-16,363$ & 66,9 \\
\hline 14 & 4,65 & $-0,90$ & 21,6 & 0,81 & 69,6 & 20,479 & $-16,363$ & 73,7 \\
\hline & & & 135 & 11 & & & $P_{\max }=$ & 106,5 \\
\hline
\end{tabular}

(Sumber: Data diolah :2018)

Kontrol distribusi beban aksial terhadap daya dukung ijin tiang tunggal pada pilecap dapat dilihat pada tabel 3 berikut:

Tabel 3 Rekap kontrol perhitungan beban aksial

\begin{tabular}{|c|c|c|c|c|c|c|}
\hline \multirow{2}{*}{ KOMBINASI } & Vy & My & $\mathrm{Mx}$ & $P / n$ & $P \max$ & $P \min$ \\
\hline & $(\mathrm{kN})$ & $\mathrm{kN} \cdot \mathrm{m}$ & $\mathrm{kN} \cdot \mathrm{m}$ & $(\mathrm{kN})$ & $(\mathrm{kN})$ & $(\mathrm{kN})$ \\
\hline Daya layan-1 & $9.747,85$ & $2.159,268$ & 0,000 & 696,275 & 770,904 & 621,646 \\
\hline Daya layan-2 & $10.447,81$ & $2.275,397$ & 0,000 & 746,272 & 824,915 & 667,629 \\
\hline Daya layan-3 & $9.281,21$ & $1.734,473$ & 0,000 & 662,944 & 722,891 & 602,996 \\
\hline Daya layan-4 & $7.414,65$ & 373,176 & 0,000 & 529,618 & 542,516 & 516,720 \\
\hline Kuat-5 & $7.414,65$ & 496,970 & 0,000 & 529,618 & 546,794 & 512,441 \\
\hline Ekstrem-6 & $9.747,85$ & $5.925,178$ & $2.061,736$ & 696,275 & $1.064,692$ & 327,858 \\
\hline
\end{tabular}

(Sumber: Data diolah :2018)

Berdasarkan tabel diatas untuk gaya aksial yang terjadi pada pile cap dapat ditahan oleh daya dukung ijin tiang tunggal. Sedangkan untuk gaya lateral yang terjadi pada tiang dapat ditahan oleh daya dukung ijin lateral. Penulangan Struktur Abutment

Berdasarkan hasil perhitungan penulangan pada struktur abutment diperoleh hasil rekap penulangan yang mana dapat dilihat pada tabel 4 di bawah ini: 
Tabel 4 Rekap Penulangan Penulis

\begin{tabular}{|c|c|c|c|c|c|}
\hline \multirow[b]{2}{*}{ NO } & & \multicolumn{4}{|c|}{ PERHITUNGAN DENGAN SNI 2016 (PENULIS) } \\
\hline & URAIAN PENULANGAN & $\begin{array}{c}\text { TULANGAN } \\
\text { UTAMA (TARIK) } \\
\end{array}$ & \begin{tabular}{|c|} 
TULANGAN \\
UTAMA (TEKAN) \\
\end{tabular} & $\begin{array}{c}\text { TULANGAN } \\
\text { SUSUT }\end{array}$ & $\begin{array}{c}\text { TULANGAN } \\
\text { GESER }\end{array}$ \\
\hline 1 & PILE CAP & D22 - 150 & D19 - 150 & D13 - 100 & \begin{tabular}{|c|} 
D13 - \\
200/200 \\
\end{tabular} \\
\hline 2 & BREAST WALL & D25 - 100 & D19 - 100 & D19 - 125 & - \\
\hline 3 & BACK WALL ATAS & D16 - 150 & D16 - 150 & D13 - 150 & - \\
\hline 4 & BACK WALL BAWAH & D19 - 150 & D16 - 150 & D13 - 150 & - \\
\hline
\end{tabular}

(Sumber: Data diolah :2018)

Dari tabel diatas hasil penulangan yang didapat, terdapat beberapa perbedaan diameter tulangan dan jaraknya dengan hasil perhitungan perencana, dengan dimana ada juga tulangan geser yang tidak ada, karena dinding abutment diperbesar sehingga tulangan geser tidak diperlukan. Perhitungan perencana dapat dilihat pada tabel 5 berikut:

Tabel 5 Rekap Penulangan Perencanaan

\begin{tabular}{|c|c|c|c|c|c|}
\hline \multirow[b]{2}{*}{ NO } & & \multicolumn{4}{|c|}{ PERHITUNGAN DENGAN SNI 2005 (PERENCANA) } \\
\hline & URAIAN PENULANGAN & $\begin{array}{c}\text { TULANGAN } \\
\text { UTAMA (TARIK) }\end{array}$ & $\begin{array}{c}\text { TULANGAN } \\
\text { UTAMA (TEKAN) }\end{array}$ & $\begin{array}{l}\text { TULANGAN } \\
\text { SUSUT }\end{array}$ & $\begin{array}{c}\text { TULANGAN } \\
\text { GESER }\end{array}$ \\
\hline 1 & PILE CAP & D19- 150 & D19- 150 & D19 - 100 & $\begin{array}{c}D 10-300 / \\
300\end{array}$ \\
\hline 2 & BREAST WALL & D25 - 120 & D25 - 120 & D16 - 150 & $\begin{array}{c}\mathrm{D} 10-150 / \\
360\end{array}$ \\
\hline 3 & BACK WALL ATAS & D16 - 150 & D16 - 150 & D13 - 150 & \begin{tabular}{|c|}
$\mathrm{D} 10-300 /$ \\
300 \\
\end{tabular} \\
\hline 4 & BACK WALL BAWAH & D19 - 150 & D16 - 150 & D13 - 150 & $\begin{array}{c}\mathrm{D} 10-150 / \\
300 \\
\end{array}$ \\
\hline
\end{tabular}

(Sumber: Data diolah :2018)

Untuk lebih detailnya hasil penulangan dapat dilihat pada perbandingan pada gambar 2 dan gambar 3 berikut ini:

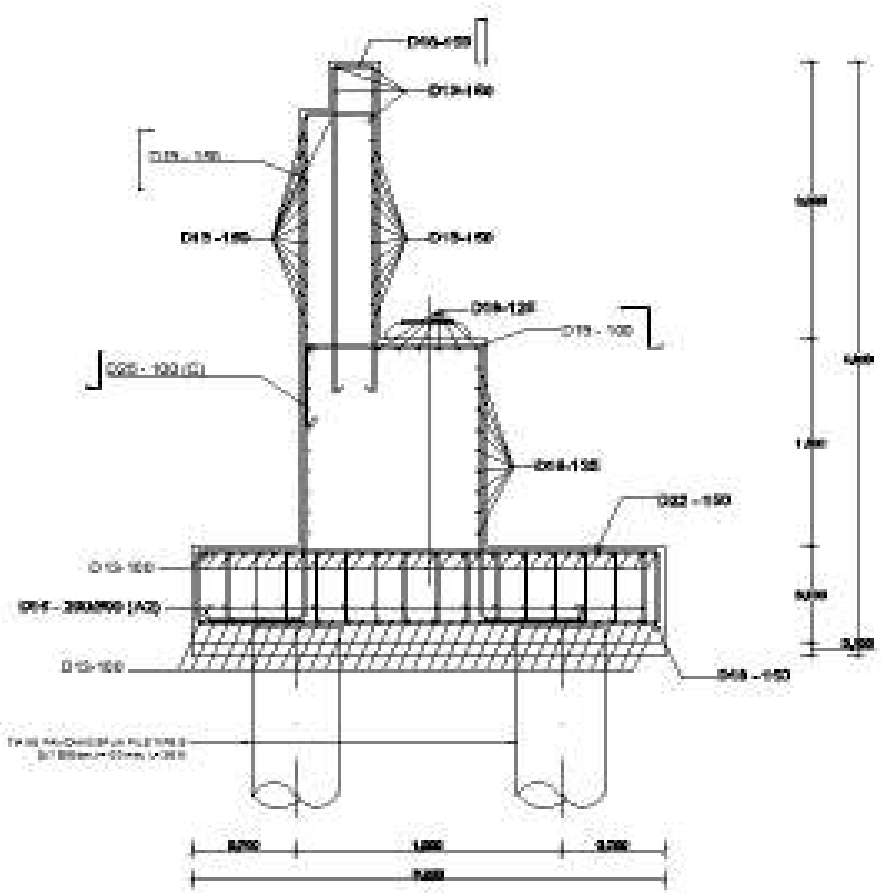

Gambar 2 Hasil Perhitungan Penulis 


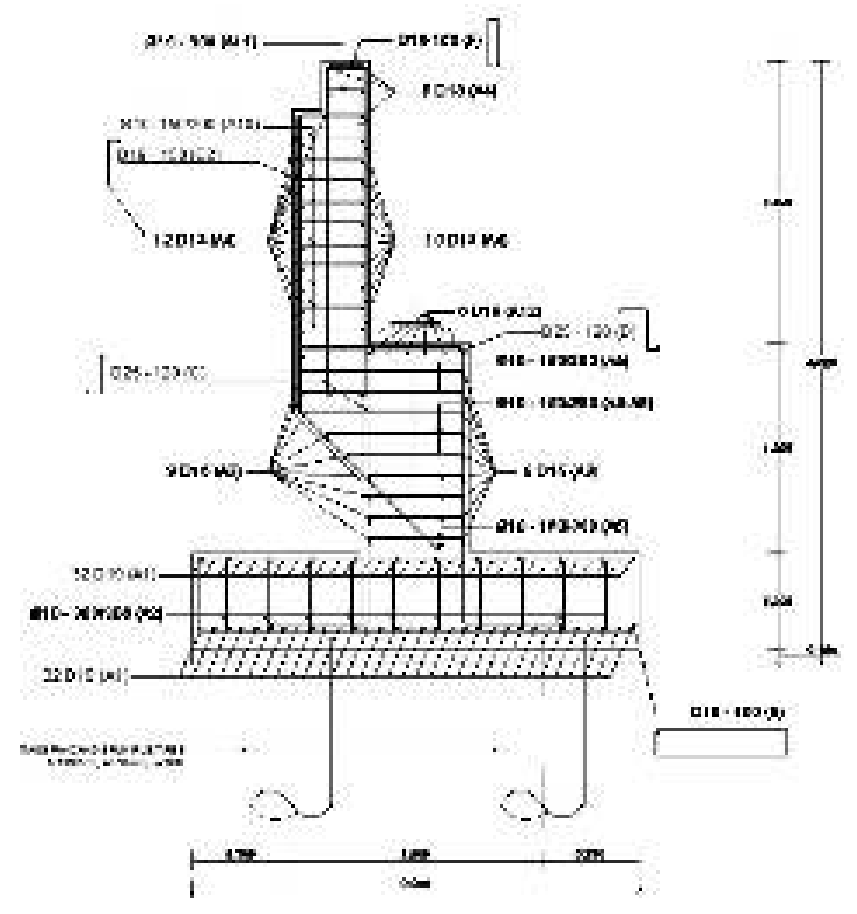

Gambar 3 Hasil Perhitungan Perencanaan

\section{KESIMPULAN DAN SARAN}

Kesimpulan

Dari analisis perhitungan bangunan bawah (sub structure) Jembatan Sungai Jinal dengan pembebanan jembatan menggunakan SNI 1725:2016 didapatkan hasil daya dukung tiang dan penulangan pada abutment sebagai berikut:

1. Perhitungan untuk daya dukung tiang pancang pada abutment berdasarkan jumlah yang di rencanakan, daya dukung tiang sudah mampu menahan gaya-gaya yang bekerja pada jembatan dengan nilai daya dukung tiang tunggal sebesar 128,6 ton.

2. Perhitungan untuk penulangan pada abutment berdasarkan dimensi yang dibuat terdapat beberapa perbedaan, adapun perbedaan tersebut dapat disimpulkan sebagai berikut:

a. Pada penulangan tarik pada pilecap terdapat perbedaan dimensi tulangan yang mana hasil perencana D19-150 sedangkan hasil perhitungan D22-150, tulangan susut hasil perencana D19-100 sedangkan hasil perhitungan D13-100, tulangan geser hasil perencana D10-300/300 sedangkan hasil perhitungan D13200/200.

b. Pada penulangan breaswall juga terdapat pebedaan pada tulangan tarik yang mana hasil perencana D25120 sedangkan hasil perhitungan D25-100, tulangan tekan hasil perencana D25-120 sedangkan hasil perhitungan D19-100, tulangan susut hasil perencana D16-150 sedangkan hasil perhitungan D19-125.

3. Perbedaan antara analisa perencana dengan analisa perhitungan penulis dapat disebabkan oleh beberapa faktor seperti:

a. Peraturan pembebanan jembatan yang digunakan (RSNI T-02-2005 dengan SNI 1725:2016).

b. Standar perencanaan ketahanan gempa untuk jembatan (SNI 2823:2008 dengan SNI 2883:2013).

c. Bentuk abutment yang berbeda.

Saran

Untuk studi selanjutnya diharapkan agar pokok bahasan lebih luas serta meninjau analisa perhitungan bangunan atas dan analisa perhitungan biaya agar penulisan ini dapat diaplikasikan langsung di lapangan.

\section{REFERENCE}

Badan Litbang PU. (2004). Standar Perencanaan Struktur Beton Untuk Jembatan (RSNI T-12-2004). Jakarta: Departemen Pekerjaan Umum.

Badan Litbang PU. (2005). Standar Pembebanan untuk Jembatan (RSNI T-02-2005). Jakarta: Departemen Pekerjaan Umum. 
Badan Litbang PU. (2008). Manual Standar Perencanaan Struktur Beton Bertulang Untuk Jembatan (No.009/BM/2008). Jakarta: Departemen Pekerjaan Umum.

Badan Litbang PU. (2016). Standar Pembebanan untuk Jembatan (SNI 1725:2016). Jakarta: Departemen Pekerjaan Umum.

Badan Litbang PU .(2018). Standar Perencanaan Ketahanan Gempa untuk Jembatan (SNI 2833:2013). Jakarta: Departemen Pekerjaan Umum.

Das, Braja M. (2011). Principles of Foundation Engineering,SI: Seventh Edition. USA: CENGAGE Learning.

Hardiyatmo, Hary Christady. (2008). Teknik Pondasi 2. Yogyakarta: Gadjah Mada University Press.

Sosrodarsono, Suyono. (1980). Mekanika Tanah dan Teknik Pondasi. Jakarta: PT. Pradnya Paramita.

Supriyadi, Bambang dan Muntohar, Agus Setyo. (2007). Jembatan. Yogyakarta: Gadjah Mada University Press. 